cases we report had blood lead values below $80 \mu \mathrm{g} /$ $100 \mathrm{ml}$ yet both cases were unequivocally suffering from lead poisoning. In addition, both cases had normal haemoglobin concentrations and so would have escaped detection by screening programmes based on the usual haemoglobin or blood lead criteria. Similar cases have been reported (Waldron, 1971; Gibson et al., 1968) and the latter authors recommended that lead concentrations greater than $60 \mu \mathrm{g} / 100 \mathrm{ml}$ should prompt further investigation.

Lead in the blood reflects absorption of the metal. Individuals vary in their susceptibility to intoxication and in practice, indices of absorption do not correlate closely with indices of intoxication (Gibson et al., 1968). It, therefore, seems logical to prefer evidence of intoxication to estimates of absorption both for occupational screening and for confirmation of clinical diagnoses. Of the investigations tabulated for these patients, the measurement of erythrocyte protoporphyrin is too difficult and that of $\delta$-amino laevulinic acid dehydrogenase activity too sensitive (Hernberg and Nikkanen, 1970) for routine use. Regular haemoglobin determinations in all statutory lead workers are required by law (Ministry of Labour, 1965). A decrement in haemoglobin concentration is evidence of significant lead poisoning, other causes having been excluded, but as shown in this report, symptomatic poisoning may coincide with normal haemoglobin values. Measurements of urinary amino laevulinic acid and urinary coproporphyrins are useful in both the industrial and the clinical context (Gibson et al., 1968; Haeger-
Aronsen, 1971). Their sensitivity is such that they become abnormal at an early stage of lead intoxication. Had our cases presented for routine occupational screening, both urinary coproporphyrin and amino laevulinic acid measurements would have recognized a state of lead poisoning; neither haemoglobin nor blood lead measurements would have recognized it.

\section{Acknowledgments}

Our thanks are due to Dr R. S. Savidge of Bury General Hospital and Professors W. R. Lee and S. W. Stanbury of Manchester University for permission to report these cases. Professor Lee and Dr P. H. Adams are responsible for many improvements in the final manuscript. We are grateful to Dr D. Walsh and the technicians of the Manchester Royal Infirmary laboratories for the chemical estimations.

\section{References}

Gibson, S.L.M., Mackenzie, J.C. \& Goldberg, A. (1968) The diagnosis of industrial lead poisoning. British Journal of Industrial Medicine, 25, 40.

HAEGER-ARONSEN, B. (1971) An assessment of the laboratory tests used to monitor the exposure of lead workers. British Journal of Industrial Medicine, 28, 52.

Hernberg, S. \& NikKanen, J. (1970) Enzyme inhibition by lead under normal urban conditions. Lancet, $\mathbf{i}, 63$.

KING, E. \& Thompson, A.R. (1961) The measurement of lead absorption in industry. Annals of Occupational Hygiene 3, 247.

LANE, R.E., ETAL (1968) Diagnosis of inorganic lead poiso ing: a statement. British Medical Journal, 4, 501.

Ministry OF LABOUR (1965) Annual Report of H.M. Chis Inspector of Factories in Industrial Health, 1964. H.M.S.O., London.

WALDRON, H.A. (1971) Correlation between some parameters of lead absorption and lead intoxication. British Journal of Industrial Medicine, 28, 195.

\title{
Acute barbiturate poisoning in young epileptics
}

\author{
B. W. HANCOCK \\ M.B., CH.B., D.C.H. \\ Neurology Unit, Fulwood Annexe, Sheffield
}

\begin{abstract}
Summary
Two young epileptic patients presenting in coma with focal neurological signs were found to be suffering from unsuspected acute barbiturate overdose. There had been strenuous denial of any possibility of psychiatric disturbance or of self-poisoning in the history obtained from their parents at the time of admission. The importance of excluding deliberate drug overdose in any young epileptic patient presenting with prolonged or atypical coma is re-emphasized.
\end{abstract}

Correspondence: B. W. Hancock, 42 Winchester Road, Sheffield S10 4EE.
Coma is a common presentation of the known $N$ epileptic patient to the acute medical unit. The following two cases are reported to emphasize the $O$ importance of excluding deliberate drug overdose in $\mathrm{\omega}$ the young epileptic patient whose presenting coma is in any way atypical or prolonged.

\section{Case 1}

A 12-year-old girl with a 2-year history of Grand Mal epilepsy was admitted to the Neurology Unit $\underset{\mathbb{D}}{\stackrel{0}{D}}$

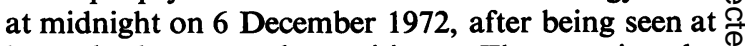
home by her general practitioner. That evening she 2 
had lapsed into coma after complaining for $2 \mathrm{hr}$ of dizziness, slurred speech, double vision and unsteadiness of gait. Her parents strenuously denied that there was any possibility of tablet overdose, but wondered if she could have injured herself whilst performing gymnastic exercises with her friends earlier in the evening. They confirmed that the patient had been taking regular anti-convulsant therapy of Phenytoin, $50 \mathrm{mg}$ twice daily and Phenobarbitone, $30 \mathrm{mg}$ twice daily and that in the months prior to her admission she had been having only occasional convulsions. At the time of admission she was comatose but apyrexial. Examination of the cardiovascular, respiratory and abdominal systems was normal. Her fundi and pupil responses were normal, there was no neck stiffness, the tendon reflexes were difficult to elicit, but the left plantar response was extensor. The history and findings were highly suggestive of a brain stem catastrophe, possibly vascular or traumatic, but a search for other remediable conditions was made. Echoencephalography, skull X-ray, blood sugar, serum urea and electrolytes and lumbar puncture were normal, but the serum barbiturate level estimated $1 \mathrm{hr}$ after admission was $8.2 \mathrm{mg} \%$. At this stage the child was transferred to the Children's Hospital for intensive care. An endo-tracheal airway was inserted, gastric lavage performed and forced alkaline diuresis commenced and continued for the next 2 days. The serum barbiturate level on the morning after admission was $9.8 \mathrm{mg} \%$ (as Phenobarbitone), and this gradually fell over the next 3 days to $4.4 \mathrm{mg} \%$, by which time the patient was regaining consciousness. When she had fully recovered she willingly admitted to having ingested more than twelve Phenobarbitone $(30 \mathrm{mg}$ ) tablets and several Phenytoin $(50 \mathrm{mg})$ capsules, but would give no reason for her behaviour. Psychiatric assessment showed her to be a depressed, withdrawn child with difficulties in adjusting to her epilepsy.

\section{Case 2}

A 15-year-old boy with a 2-year history of Grand Mal epilepsy was admitted to an acute medical unit on the morning of 9 January 1973, with a history of unconsciousness following a convulsion. During the previous night he had been observed by his mother to have what she thought was a convulsion. He had remained unrousable throughout the night and next morning. His regular anti-convulsant therapy had been Phenytoin, $50 \mathrm{mg} 8$ hourly and Phenobarbitone $60 \mathrm{mg}$ at night. The parents gave no indication of domestic problems and discounted any possibility of drug overdose. Examination at the time of admission, about $8 \mathrm{hr}$ after the supposed convulsion, showed the patient to be unrousable but no other abnormalities were found. Skull X-ray, chest X-ray, serum urea and electrolytes and blood sugar investigations were all normal and a serum barbiturate level was found to be $2.4 \mathrm{mg} \%$ (consistent with regular medicinal doses of Phenobarbitone). The provisional diagnosis of prolonged post-ictal coma was made and the patient observed. There was no change in the conscious state over the next $24 \mathrm{hr}$, but tendon reflexes became difficult to elicit and the left plantar response became extensor. At this stage the patient was transferred to the Neurology Unit for further investigation. Echoencephalography and lumbar puncture were normal but a repeat serum barbiturate estimation showed a level of $9.6 \mathrm{mg} \%$ (as Phenobarbitone). By this time the patient's condition was slowly improving and he was treated expectantly. On the following day the serum barbiturate level had fallen to $5.4 \mathrm{mg} \%$ and the patient was fully rousable, though still drowsy. When he had completely recovered, the boy admitted to having ingested approximately thirty Phenobarbitone (30 $\mathrm{mg}$ ) tablets on the evening before admission. Psychiatric assessment confirmed reactive depression to problems at home and at work.

\section{Comments}

The usual causes for the known epileptic patient to be admitted to hospital in coma are status epilepticus, prolonged post-ictal unconsciousness and head injury occurring at the time of a convulsion.

It is well recognized that epileptic patients may attempt suicide (Kessel, 1965) since they often have associated psychiatric disturbance (Scott, 1968), but in both of the above patients the possibilities of psychiatric instability and of deliberate drug overdose were discounted by the parents at the time of admission.

In Case 1, the presenting history and physical findings indicated an acute neurological cause for the coma. Fortunately, a serum barbiturate level was requested and this revealed the true nature of the problem. This patient ingested an overdose of Phenytoin as well as Phenobarbitone, and ataxia, vertigo and dysarthria (her presenting features) are recognized acute toxicity effects of both of these drugs (Graham, 1962).

In Case 2, the history and examination at the time of admission were consistent with post-ictal coma, but the period of unconsciousness following the suspected single convulsion (usually no longer than an hour, Elliott, 1964) was prolonged and latedeveloping signs once again suggested a neurological cause. In this case, although a later estimation confirmed the overdose, the initial serum barbiturate level $(2.4 \mathrm{mg} \% 12 \mathrm{hr}$ after ingestion) was within the limits normally accepted for epileptic patients taking regular Phenobarbitone therapy. Serum levels of between 1.5 and $3.5 \mathrm{mg} \%$ are normally accepted, 
but levels of up to $6 \mathrm{mg} \%$ have been recorded (Lous, 1954).

Undoubtedly, acute barbiturate toxicity is associated with the development of neurological signs, such as depressed tendon reflexes and extensor plantar responses (Carroll, 1969) but it is of interest that both patients showed these changes without gross respiratory or cardiovascular depression.

Following recovery from coma, both patients admitted taking an overdose of drugs and both were found to be psychiatrically disturbed, much to the surprise and chagrin of their parents who, at the time of admission, had unwittingly misled the attendant medical staff.

Acute barbiturate poisoning should therefore be considered in any epileptic patient presenting with atypical coma, even when there is no evidence of possible overdose or of psychiatric instability.

\section{Acknowledgments}

I am grateful to Dr E. W. J. Gumpert for his encouragement and to Dr Gumpert and Dr J. Carson for allowing me to report details of their patients.

\section{References}

Carroll, B.J. (1969) Barbiturate overdosage-presentation $\overline{\bar{O}}$ with focal neurological signs. Medical Journal of Australia, $\vec{\nabla}$ $1,1133$.

Elliotr, F.A. (1964) Clinical Neurology. 1st Edition, p. 64. ปู Philadelphia: Saunders.

GraHAM, J.D.P. (1962) The Diagnosis and Treatment of $\vec{\circ}$ Acute Poisoning, pp. 107, 137. London: Oxford Uni- $\vec{\exists}$ versity Press.

KESSEL, N. (1965) Self poisoning. British Medical Journal, 2, 1265.

Lous, P. (1954) Blood serum and cerebrospinal fluid levels and renal clearance of phenobarbitone in treated epileptics. Acta Pharmacologica et Toxicologica, 10, 166.

Scotr, D.F. (1968) Psychiatric aspects of epilepsy. Postgraduate Medical Journal, 44, 319.

\section{Ergotamine-induced venous thrombosis}

U. MiNTZ
M.D.
S. BAR-MEIR

M.D.

\section{Summary}

A patient is described who developed venous thrombosis in the leg following an intramuscular injection of ergotamine tartrate.

\section{Introduction}

Ergotamine poisoning in the human classically manifests as arterial spasm and arterial thrombosis, sometimes leading to gangrene of the extremities. We wish to report a rare vascular complication of ergotamine treatment, venous leg thrombosis which appeared in a woman following an intragluteal injection of ergotamine tartrate given for menorrhagia.

\section{Case report}

The patient, a female teacher, aged 38 years, mother of two healthy children, was admitted with the complaint of pain in her left calf. Four days earlier she had severe migraine and took $5 \mathrm{~g}$ of aspirin instead of the ergotamine tartrate tablets she was wont to use but which were out of stock. The next morning, on the expected day, her menstruation started, this time, however, with excessive blood loss to an extent she had never experienced before. The $\frac{7}{2}$ severe menorrhagia continued for 3 days until at 10.30 a.m. on the day of admission she received an $N$ intragluteal injection of $0.5 \mathrm{mg}$ ergotamine tartrate. Three quarters of an hour later she felt a cramp in the neck muscles and a sensation of severe burning $\omega$ pain radiating along both thighs downward. On lying down the burning pain disappeared but when $\stackrel{\circ}{\circ}$ she tried to rise at 13.00 p.m. she felt a sharp pain $\Phi$ in the left calf preventing her from standing. Since $?$ the pain continued unabated she was admitted at ${ }_{0}$ 18.30 p.m. Noteworthy in her history are frequent $\frac{\vec{D}}{\mathrm{D}}$ attacks of severe migraine of many years duration for which she had been taking various analgesics, $\stackrel{\AA}{\varrho}$ 